\title{
Distribution and population recovery of Arenicola marina and other benthic fauna after bait digging
}

\author{
D. S. McLusky, F. E. Anderson* and S. Wolfe-Murphy \\ Department of Biology, The University of Stirling, Stirling FK9 4LA, Scotland
}

\begin{abstract}
Effects of bait digging on distribution and population recovery of Arenicola marina, Hydrobia ulvae and Macoma balthica have been investigated on trial plots at Blackness, Forth estuary (Scotland). A. marina rapidly recolonised the basins created by digging, but had reduced populations on the dug mounds. Its populations were dislocated for over $3 \mathrm{mo}$ after digging. $H$. ulvae and $M$. balthica showed enhanced populations on the mounds for up to $2 \mathrm{wk}$, but were otherwise unaffected by digging. Factors influencing the mode of population recovery are discussed; it is suggested that enhanced basin populations of recolonising $A$. marina are due substantially to above-surface migration of worms into areas with increased levels of organic matter.
\end{abstract}

\section{INTRODUCTION}

Bait digging by sport fishermen is a widespread practise. In Britain it is estimated that $75 \%$ of the members of the National Anglers Coucil dig their own bait. The ragworms Nereis spp. and the lugworm Arenicola marina (L.) are dug as a commercial commodity (Nature Conservancy Council, 1979). In Maine, USA, baitworm digging (mainly Glycera dibranchiata) is the fifth largest fishery in terms of total dollar value, being only exceeded by lobsters, fin fish, clams and scallops, and employing 1188 diggers (Schroeder, 1978). Dijksterhuis (pers. comm.) has calculated that the annual landings of $A$. marina from the Dutch Wadden Sea by mechanical bait digging range from 29 to $36 \times 10^{6}$ worms $\mathrm{yr}^{-1}$; compared to the total lugworm population in this area of about $4000 \times 10^{6}$, this is less than $1 \%$ of the population.

Blake (1979) compared an exploited (dug) population of Arenicola marina (hereafter Arenicola or lugworm) with an unexploited population at Whitley Bay, N. E. England, and concluded that due to the relative inefficiency of the diggers, the lugworm populations were not threatened by bait digging. He did not, however, follow the pattern of population recovery in detail. That bait digging for lugworms affects other benthic species was shown by Jackson and James

- Present address: Dept. of Earth Science, University of New Hampshire, Durham, N.H., USA
(1979) who found that bait digging for Arenicola caused cockles, Cerastoderma (= Cardium) edule (L.), to be either buried below $10 \mathrm{~cm}$ depth, or else left on the surface. Both circumstances are usually lethal for the cockle. They concluded that cockle populations will not flourish, and may completely disappear, in areas disturbed by bait digging. Comparable problems have been shown by Canadian workers (Levings et al., 1978) who studied the effect of digging a ditch for an electric cable across the Fraser River Delta estuary and reported the depression in the abundance of macroinvertebrate species adjacent to the ditch, but also the creation of new micro-habitats for some species utilising plant debris which accumulated in the ditch.

The present paper reports on the effects of bait digging on the distribution and population recovery of Arenicola and other benthic species - Macoma balthica (L.) and Hydrobia ulvae (Pennant) - on trial digging plots at Blackness, Forth estuary, E. Scotland. This study was conducted in parallel with a study of the effects of bait digging on estuarine sedimentation (Anderson and McLusky, 1981).

\section{MATERIALS AND METHODS}

The study was conducted on an intertidal mud flat located east of the village of Blackness, in the lower reaches of the Forth estuary $\left(56^{\circ} 0^{\prime} \mathrm{N}, 3^{\circ} 30^{\prime} \mathrm{W}\right)$. This flat is approx $1 \mathrm{~km}$ from low tide to high tide mark, 
with a rich population of Arenicola at and above midtide level. The area is relatively unpolluted, and is over $8 \mathrm{~km}$ downstream of industrial effluents which affect the upper and middle Forth estuary (McLusky, 1982).

At the commencement of each experiment the area was dug by hand spade in a manner similar to digging by bait diggers, which entailed digging holes about 15 to $20 \mathrm{~cm}$ deep and 40 to $50 \mathrm{~cm}$ diameter, removing any Arenicola found, and then depositing the mud removed as a mound adjacent to the basin.

Experiment 1 . An area of $10 \times 10 \mathrm{~m}$ was dug over on October 6, 1980. The density of Arenicola before and after digging was measured by counting the lugworm casts in a $50 \times 50 \mathrm{~cm}$ quadrat placed on the mud surface. Counts were repeated 10 times at random for each habitat (mound or basin) and for an adjacent control site, and the mean density determined. Cores of mud $(5 \times 5 \times 5 \mathrm{~cm})$ were also collected in duplicate from mounds, basins and control site. These samples were sieved through a $300-\mu \mathrm{m}$ sieve; the material retained was examined under a binocular microscope and any animals present (mostly Macoma balthica and Hydrobia ulvae) were identified and counted. Samples were collected before and after digging on October 6, and at regular intervals for up to $46 \mathrm{~d}$ therafter for cores, and for $138 \mathrm{~d}$ for Arenicola counts

Experiment 2. An area of $20 \times 20 \mathrm{~m}$ was dug over on January 6,1981 . Part of the area was bait-dug on the mound/basin method as in Experiment 1. Another part of the area was dug by a trench method whereby the mud which had been dug to remove Arenicola was placed back in the same trench. The trench was 40 to $50 \mathrm{~cm}$ in width. This method is referred to as the 'infill' sites. Arenicola numbers were counted by quadrat for $92 \mathrm{~d}$ as per Experiment 1 .

Experiment 3. An area of $20 \times 25 \mathrm{~m}$ was dug over on September 23, 1981. Arenicola cast counts were made as per Experiments 1 and 2, although this

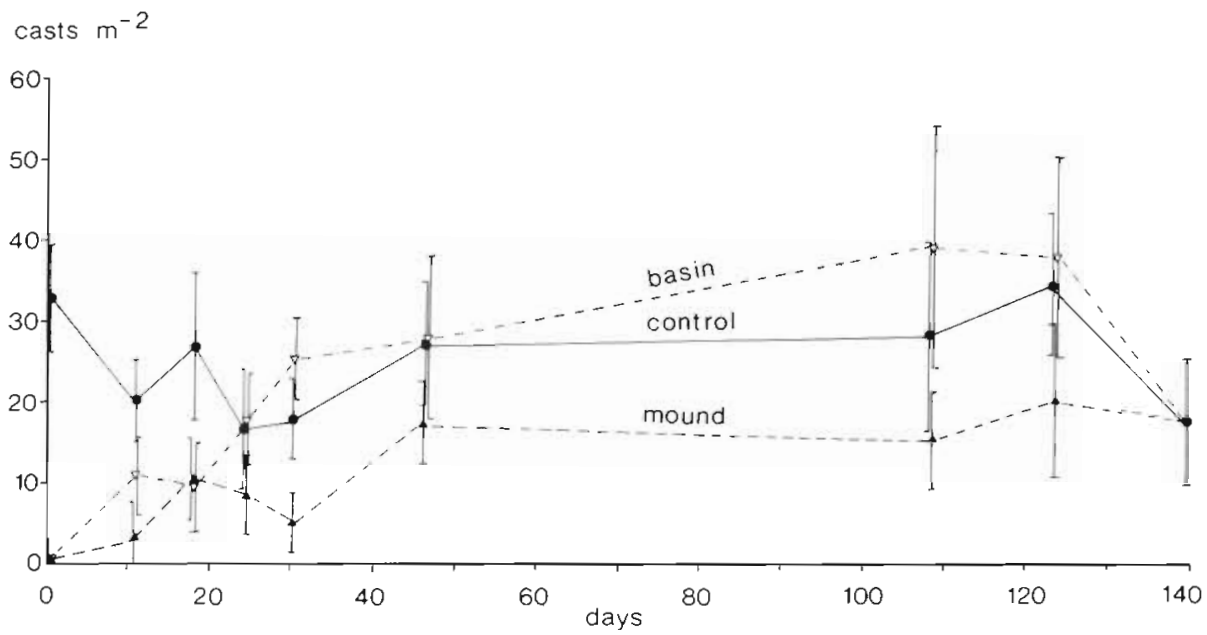

Fig. 1. Experiment 1 Number of Arenicola marina casts $\mathrm{m}^{-2}$ in control, basin and mound habitats, in relation to number of days after digging. Vertical bars: standard deviation time up to 100 random counts were made of each habitat, for a period of $84 \mathrm{~d}$. Two alternatives for recolonisation are available to the lugworms, either burrowing through the substrate, or swimming at high tide. In order to distinguish these modes of movement metal barriers were placed into intertidal mud adjacent to the experimental site. Two open-ended cubes of $0.5 \mathrm{~m}$ side were installed on mud cleared of Arenicola, one above the surface limiting above-surface migration, and one submerged to prevent subsurface migration.

Apart from faunistic sampling mentioned above, samples of surface sediment were simultaneously collected during some experiments for textural analysis, and the analysis of carbon and nitrogen using a PerkinElmer elemental analyser. Regular measurements of temperature and salinity were made. The profile of selected mounds and basins was followed throughout the study. The detailed methodology of these physical parameters are presented elsewhere (Anderson and McLusky, 1981). Comparison between results from different sites was made by use of a standard paired ' $t$ ' test, with significant differences based at the $95 \%$ level $(P=<0.05)$

\section{RESULTS}

\section{Experiment 1}

The density of Arenicola in the study area was 32.8 individuals $\mathrm{m}^{-2}$ initially, and during the succeeding $138 \mathrm{~d}$ the control value was within the range of 16.8 to $34.0 \mathrm{~m}^{-2}$. The Arenicola counts are based on casts, and the variability within the control may be due to factors such as temperature, rainfall or tidal state affecting cast formation in Arenicola.

The numbers of Arenicola in the mound area fell to zero immediately after digging, and gradually rose to a density of $50 \%$ of the control after $24 \mathrm{~d}$ (Fig. 1). Num- 
bers of worms in the mound sites remained significantly lower than the control even after $122 \mathrm{~d}$ ( $\mathrm{t}=$ 3.227, $\mathrm{P}<0.005$ ). By $138 \mathrm{~d}$ after digging, it was impossible to distinguish between mounds and basins and the experiment was terminated.

The numbers of Arenicola in the basins remained low for the first $2 \mathrm{wk}$ after digging; however, by the 24 th day the numbers in the basin were not significantly different from the control $(t=0.390, P>0.05)$. By the 30th day the numbers in the basin were significantly greater than the control $(t=3.162, \mathrm{P}<0.005)$; however, from Day 45 until the termination of the experiment there was no significant difference between control and basin numbers of lugworm.

The density of Hydrobia ulvae in the area before digging was $2400 \mathrm{~m}^{-2}$. Following digging the numbers of Hydrobia in the basins remained low for $5 \mathrm{~d}$, at 0 to $400 \mathrm{~m}^{-2}$. By the 8 th day the numbers in the basin increased to $1200 \mathrm{~m}^{-2}$, and then steadily increased to $3000 \mathrm{~m}^{-2}$ by Day 31. (Fig. 2). The numbers of $H$. ulvae

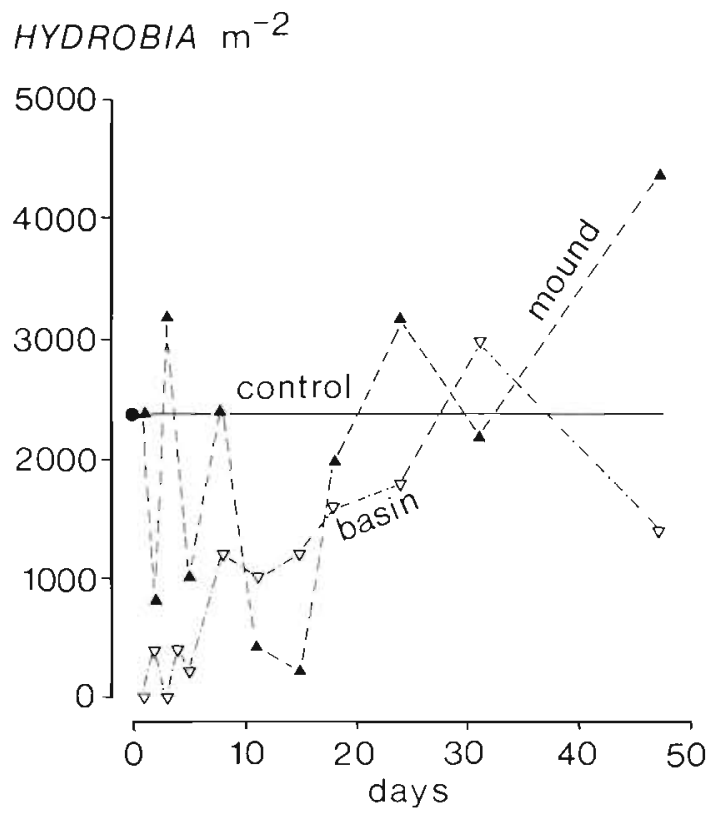

Fig. 2. Experiment 1. Number of Hydrobia ulvae $\mathrm{m}^{-2}$ in control, basin and mound habitats, in relation to number of days after digging

on the mound appear to have been little affected by the digging; $24 \mathrm{~h}$ after digging the numbers on the mound were $2400 \mathrm{~m}^{-2}$, the same as the control, and during the succeeding days they stayed at or near that level, except for a brief decline on Days 11 to 15 .

The density of Macoma balthica was initially $400 \mathrm{~m}^{-2}$. Following bait digging the numbers in the basin were virtually 0 for $11 \mathrm{~d}$, but from Day 15 onwards the numbers in the basin increased, and showed a considerable overlap with the numbers on the mound (Fig. 3). The numbers of $M$. balthica in the mounds was double the control level for $11 \mathrm{~d}$ after digging, and then fell to a level indistinguishable from the basin from Day 15 onwards.

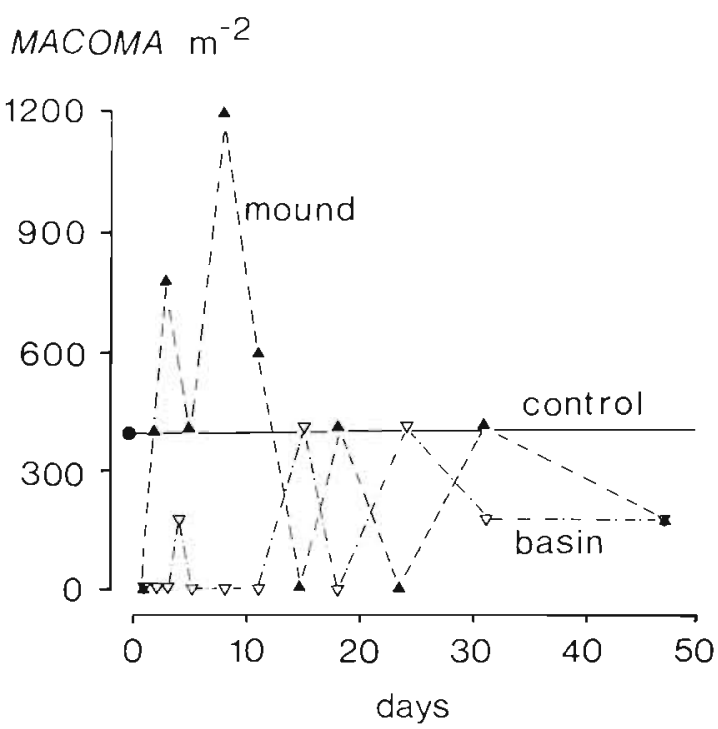

Fig. 3. Experiment 1. Number of Macoma balthica $\mathrm{m}^{-2}$ in control, basin and mound habitats, in relation to number of days after digging

\section{Experiment 2}

The initial density of Arenicola at the commencement of the second experiment was $22 \mathrm{~m}^{-2}$. The numbers in basin, mound and infill areas were all reduced to 0 by the digging. Those in the mound remained at a low density, being still under $50 \%$ of the control at $92 \mathrm{~d}$ (Fig. 4). The numbers in the mound were significantly less than the control throughout the experiment $(t=3.801-7.094, P=<0.003)$. As in the first experiment the numbers in the basin increased rapidly, until there was no significant difference between the control and the basin at Days 15 to $34(\mathrm{t}=0.00-1.975, \mathrm{P}$ $>0.05$ ). Over the period sampled by Days 49 to 92 , the numbers in the basin were significantly greater than the control $(\mathrm{t}=2.340-5.401, \mathrm{P}<0.002)$.

The numbers of Arenicola in the infill areas built up rapidly after digging, and after Day 22 the infill area was statistically indistinguishable from the control area. The infill area maintained differences from the mound and basin areas in a manner comparable to control sites.

\section{Experiment 3}

The initial density of the Arenicola at the commencement of the third experiment was $39.6 \mathrm{~m}^{-2}$. The numbers in the control area remained in the range 39.7 


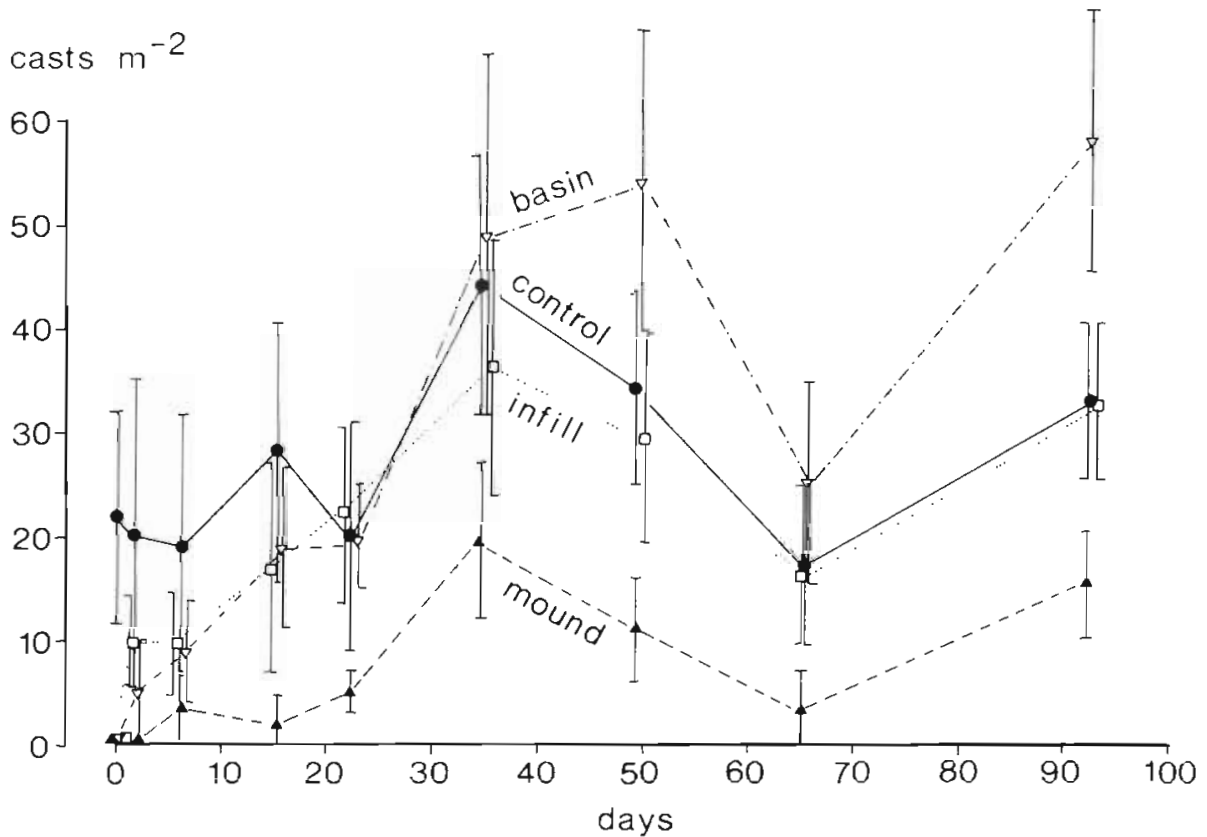

Fig. 4. Experiment 2. Number of Arenicola marina casts $\mathrm{m}^{-2}$ in control, basin, mound and infill habitats, in relation to number of days after digging. Vertical bars: standard deviation to $30.1 \mathrm{~m}^{-2}$. The numbers of Arenicola in the basin increased steadily over the first $4 \mathrm{wk}$. From Day 51 to Day 84 there was no significant difference between control and basin numbers (Fig. 5$)(t=0.60-1.61, P$ $>0.05$ ).

The numbers of Arenicola in the mound area fell to 0 after digging, and then increased slowly, being $7.56 \mathrm{~m}^{-2}$ on Day 22, $9.81 \mathrm{~m}^{-2}$ on Day 37, and $19.32 \mathrm{~m}^{-2}$ on Day 84 at the termination of this experiment. In all cases the numbers of Arenicola in the mounds was significantly below the control numbers $(t=9.37-$ 26.68, $\mathrm{P}<0.000$ ).

During this experiment sediment samples were collected for carbon and nitrogen analysis. The results

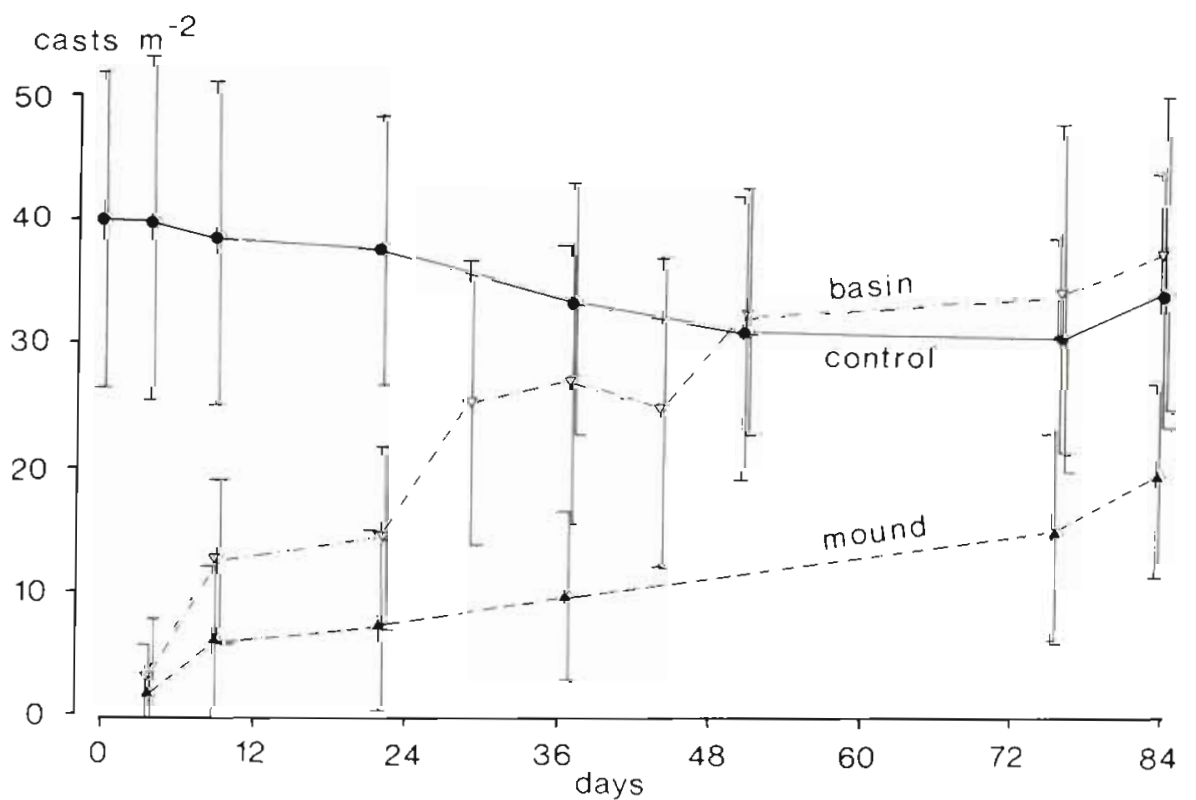

(Fig. 6) show enhanced $C$ and $N$ in the basins during Days 29 to 51, and depressed $\mathrm{C}$ and $\mathrm{N}$ in the mounds throughout the study.

Placing surface and sub-surface barriers showed that the area with a subsurface barrier was recolonised considerably more rapidly than the area with an above-surface barrier (Table 1).

\section{DISCUSSION}

The Arenicola counts $\mathrm{m}^{-2}$ are based on casts, and variability within the results may be due to factors such as temperature, rainfall or tidal state affecting cast

Fig. 5. Experiment 3. Number of Arenicola marina casts $\mathrm{m}^{-2}$ in control, basin and mound habitats, in relation to number of days after digging. Vertical bars standard deviation 
Fig. 6. Experiment 3. Percentage of carbon and nitrogen in sediment samples collected from control, basin and mound habitats, in relation to number of days after digging

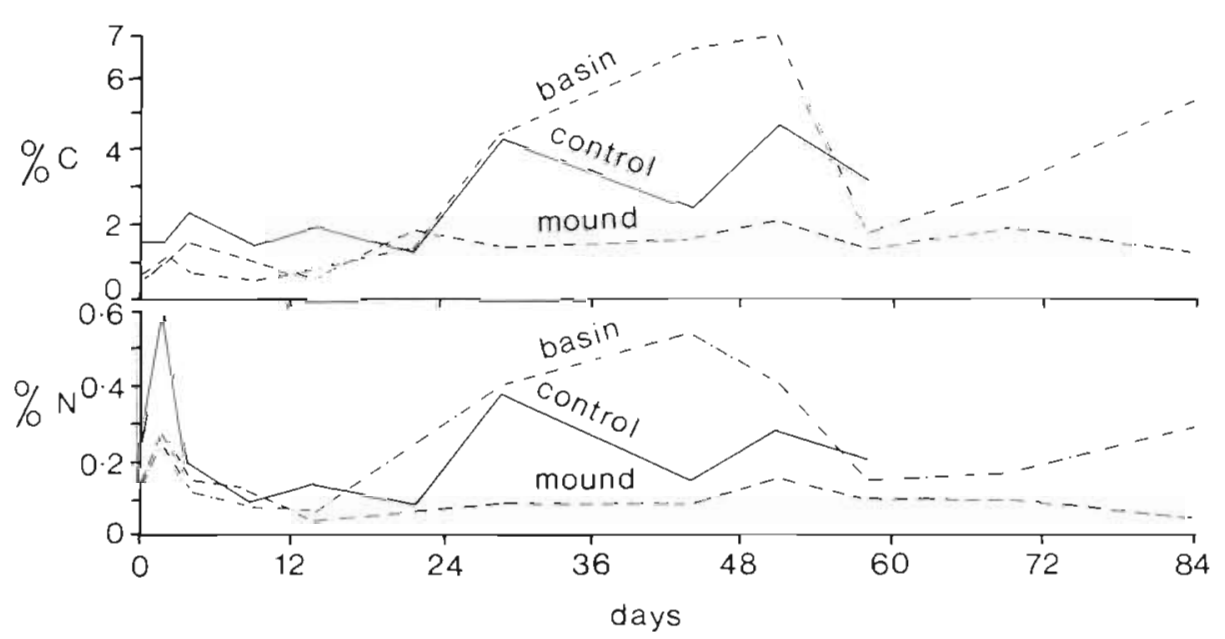

Table 1. Arenicola marina. Movement into areas which had been depopulated, and then surrounded by an open-ended metal cube of $0.5 \mathrm{~m}$ side placed either above surface or submerged below the surface. Numbers expressed as worm casts $0.25 \mathrm{~m}^{-2}$ Experiment started 29 Oct 1981

\begin{tabular}{|llllllll|}
\hline Days since barrier installation: & 0 & 7 & 14 & 21 & 33 & 39 \\
\hline Casts within above-surface barrier & 0 & 1 & 1 & 2 & 2 & 2 \\
Casts within below-surface barrier & 0 & 3 & 4 & 4 & 4 & 6 & 5 \\
\hline
\end{tabular}

formation. However, the surface-quadrat method permits a far larger area to be sampled than any method requiring manual digging, and it does permit a valid comparison between different parts of the experimental plot on any one day since every part experienced the same weather. Longbottom (1970) and Cadee (1976) have considered the problem of sampling Arenicola, and finding good correlations between lugworm numbers and cast presence have used casts as the basis of their sampling technique.

The results have shown that the population distribution of Arenicola is markedly affected by bait digging. The pattern of recovery is quite different between mound and basin habitats. In the mound environment, numbers remained low throughout the recovery period, being only $50 \%$ of the control populations at $80+$ days in all 3 experiments. Equality with the controls was only experienced in Experiment 1 which continued until the mounds were completely obliterated. By contrast, the basins were rapidly reoccupied. The basins had populations equal to the controls by Day 24, Day 15 and Day 51 in the 3 experiments. The figures indicate that the basin population exceeded the controls during the latter part of each experiment, although the enhanced basin population was not statistically significant in Experiment 3. The area dug by the 'infill' method was indistinguishable from the control within $22 \mathrm{~d}$.

Blake (1978) found that approximately 1 mo was required for a 'dug-out' area of an Arenicola beach to be repopulated to something like its original density. His study did not distinguish the mode or area of repopulation. The present study has shown that basins and infill area are fully repopulated within $1 \mathrm{mo}$, whilst the mounds have depressed populations as long as they exist. During the 2- to 3-mo period after digging the basins had enhanced populations of lugworms. This enhancement of basin populations, coupled with depression of mound populations, means that it would be valid to suggest that the total beach population of Arenicola is repopulated within $1 \mathrm{mo}$ after digging, but not uniformly distributed until basins and mounds are completely obliterated.

Records of the physical profile of mounds and basins (Anderson and McLusky, 1981) showed that the mounds eroded slowly at a rate of 0.10 to $0.17 \mathrm{~cm} \mathrm{~d}^{-1}$, while the basins filled more rapidly by bedload movement at rates between 0.55 and $0.61 \mathrm{~cm} \mathrm{~d}^{-1}$. The most rapid topographic changes occurred during the first fortnight of each experiment; however, there was still evidence of bottom disturbance 4 mo after the first experiment. In general the digging process created a different textural environment, with coarse-grained sand mounds and basins surrounded by finer silt-rich sand. The main environmental factors which enhanced the physical recovery of the tidal flat were a combination of rainfall and wind-driven waves, the latter being strictly controlled by fetch directions in the study area. 
The basins thus quickly accumulated sediment by suspension settling and by bedload transport. Once the basins were $2 / 3$ filled (approx. $14 \mathrm{~d}$ ) fine sediments were no longer trapped, and the basins remained floored with sandy deposits. In addition to trapping sediment the basins also trapped organic matter such as seaweed debris, which contributed substantially to the enhanced levels of carbon and nitrogen noted in basins for Days 29 to 51 of Experiment 3. The accumulation of plant debris in intertidal depressions was also noted by Levings et al. (1978), who noted aggregations of amphipods and isopods among the plant debris in mechanically dug trenches.

The mounds were relatively resistant to erosion and maintained a measurable micro-relief for months after digging. During this period the organic content of the sediment on the mounds had depressed values as measured by carbon and nitrogen analysis.

Longbottom (1970) concluded that the nutritional value of the sediment is the major factor in the distribution of Arenicola, and the absence from coarse sediments is mainly due to insufficient food in such sediments. In an earlier study at the same site Chapman and Newell (1949) described the distribution of Arenicola as being determined by sediment softness and the associated ease of burrowing. The present study has shown an enhanced attractiveness of the basin environment compared to the mounds. The basins represent discrete pockets of softer, coarser and organically-enriched sediment. Since both mounds and basins represented coarser sedimentary environments than the control areas, it would appear that particle size is not the cause of the basins attractiveness for recolonisation. Preliminary penetrometer readings conducted during Experiment 3 indicate that the basins were softer than the control area, which was in turn softer than the mounds. Fig. 6 has shown that the basins had increased organic matter once the period of initial sediment filling had taken place. This enhanced organic matter is due to the basins acting as traps for organic debris. In contrast, the mounds had depressed organic matter levels throughout the study, which may be attributed to the continual erosion that the mounds were subjected to. Following Longbottom's study (1970) we may suggest that the enhanced basin populations of recolonising Arenicola is due substantially to the enhanced levels of organic matter in the basin environment, coupled with the softer sediment permitting easier burrowing.

The results of the barrier experiment, where an area with a sub-surface barrier was recolonised more rapidly than an area with an above-surface barrier, suggests that swimming (above-surface migration) is the most probable mechanism for recolonisation by Arenicola of areas disturbed by bait digging for lug- worms. This view is supported by the studies of Trevor (1978) who made dynamic measurements of the energy expended by Arenicola during burrowing and concluded burrowing is an expensive mode of locomotion. The recolonisation of a dug-out area of beach by above-surface adult migration of worms was postulated by Blake (1979), and the present study gives evidence to support this conclusion.

Grant (1981) investigated the recolonisation of a high-energy sandflat, and found that whereas surface dwellers appeared a single day after disturbance, deeper-living forms did not colonise until after 23 tidal days. Recolonisation was apparently related to active preference, rather than passive hydrodynamic sorting.

In contrast to Arenicola which recolonised the basins first, the other species studied, Hydrobia ulvae and Macoma balthica, recolonised the mounds first. $H$. ulvae is known to be a mobile species with a propensity to climb up objects on an intertidal area (Anderson, 1971). Barnes (1981) has reviewed this climbing behaviour; he considers that climbing is a normal feeding activity carried out in a vertical or oblique plane, rather than a strategy to facilitate dispersal. Nevertheless, it can be seen that following disturbance by digging it rapidly recolonises higher surfaces such as the mounds, and was slower to recolonise the basins.

The results show that Macoma balthica was physically removed from the basin site by digging. The mud deposited in the mound was inhabited by $M$. balthica, and this population was added to the population living in the mud upon which the mound was deposited, hence the observed population doubling. This situation persisted for $11 \mathrm{~d}$, but between Days 11 and 15 a migration took place and the clams redistributed themselves more evenly within the intertidal environment.

Digging for Arenicola was found to have a deleterious effect on Cerastoderma edule populations in Norfolk, England (Jackson and James, 1979). The present study has not shown any deleterious effects on populations of benthic animals, other than Arenicola, since Macoma balthica, and Hydrobia ulvae showed enhanced mound populations at first, and then redistribution within 2 wk such that no difference between the sites could be distinguished in terms of these species, even though the sites were still well distinguished physically. Both $H$. ulvae and $M$. balthica are known to be highly adaptable animals, able to cope with the variable ecological situations found in estuaries (Barnes, 1981; McLusky and Elliott, 1981), and this ecological resilience appears to render them largely unaffected by bait digging.

It may thus be concluded that bait digging by sport fishermen for lugworm does cause substantial dislocation of Arenicola populations. Mounds created by dig- 
ging are not fully repopulated until they are obliterated by erosion, which took over 4 mo to accomplish in the present study. By contrast, the basins created by digging form a softer and organically richer microhabitat which proves to be attractive to repopulating worms. It is suggested that population recovery is accomplished largely by the above-surface migration of adult worms. Bait digging by the 'infill' method produced the most rapid recovery of worm populations to their normal level. It may thus be seen that bait digging for Arenicola causes temporary disruption and re-distribution of lugworm populations, rather then permanent damage.

Acknowledgements. This study was supported in part by a grant from the Natural Environment Research Council. We wish to thank John Boyd for his valuable assistance.

\section{LITERATURE CITED}

Anderson, A. (1971). Intertidal activity, breeding and the floating habit of Hydrobia ulvae in the Ythan estury. J. mar. biol. Ass. U. K. 51:423-437

Anderson, F. E., McLusky, D. S. (1981). Physical recovery of an intertidal area disturbed by baitworm havesting. Report to Natural Environment Research Council, Ref GR 3/4061, p. $1-52$

Barnes, R. S. K. (1981). Behavioural activities and ecological strategies in the intertidal gastropod Hydrobia ulvae. In: Jones, N. V., Wolff, W. J. (eds.) Feeding and survival strategies of estuarine organisms. Plenum Press, New York, p. 79-90

Blake, R. W. (1979). Exploitation of a natural population of
Arenicola marina (L.) from the north-east coast of England. J. appl. Ecol. 16: 563-670

Cadee, G. C. (1976). Sediment reworking by Arenicola marina on tidal flats in the Dutch Wadden Sea. Neth. J. Sea Res. 10: 440-460

Chapman, G., Newell, G. E. (1949). The distribution of lugworms Arenicola marina over the flats at Whitstable. J. mar. biol. Ass. U. K. 28: 627-634

Grant, J. (1981). Sediment transport and disturbance on an intertidal sandflat: infaunal distribution and recolonization. Mar. Ecol. Prog. Ser. 6: 249-255

Jackson, M. J., James, R. (1979). The influence of bait digging on cockle, Cerastoderma edule, populations in north Norfolk. J. appl. Ecol. 16: 671-679

Levings, C. D., Armour, R., McDaniel, N. G. (1978). A trench through mudflat communities of macroinvertebrates on Roberts Bank, Fraser River Delta, B. C. Fish. Mar. Serv. MS Rep. 1501, p. 1-51

Longbottom, M. R. (1970). The distribution of Arenicola marina (L.) with particular reference to the effects of particle size and organic matter of the sediments. J. exp. mar. Biol. Ecol. 5: 138-157

McLusky, D. S. (1982). The impact of petrochemical effluent on the fauna of an intertidal estuarine mudflat. Estuar. coast. Shelf Sci. 14: 489-499

McLusky, D. S., Elliott, M. (1981). The feeding and survival strategies of estuarine molluscs. In: Jones, N. V., Wolff, W. J. (eds.) Feeding and survival strategies of estuarine organisms. Plenum Press, New York, p. 109-121

Nature Conservancy Council (1979). Nature conservation in the marine environment. Report of Joint Working Party on Marine Wildlife Conservation

Schroeder, P. B. (1978). Maine worm industry unhappy with state research. Natl Fisherman (June issue) 29-32

Trevor, J. H. (1978). The dynamics and mechanical energy expenditure of the polychaetes Nephtys cirrosa, Nereis diversicolor, and Arenicola marina during burrowing. Estuar. coast. mar. Sci. 6: 605-619 